Article

\title{
Capturing Waste or Capturing Innovation? Comparing Self-Organising Potentials of Surplus Food Redistribution Initiatives to Prevent Food Waste
}

\author{
Charlotte A. Spring ${ }^{1, *(1)}$ and Robin Biddulph ${ }^{2}$ (i) \\ 1 Department of Geography, University of Calgary, Calgary, AB T2N 1N4, Canada \\ 2 Department of Economy \& Society, University of Gothenburg, 40530 Gothenburg, Sweden; \\ robin.biddulph@geography.gu.se \\ * Correspondence: charlotte.spring@ucalgary.ca
}

Received: 3 April 2020; Accepted: 13 May 2020; Published: 22 May 2020

\begin{abstract}
The context for this article is the rapid international growth of (surplus) food redistribution initiatives. These are frequently reliant on networks of volunteer labour, often coordinated by digital means. Movements with these characteristics are increasingly viewed by researchers, policymakers and practitioners as cases of self-organisation. The article explores the nature and extent of self-organisation in food redistribution initiatives. Two contrasting UK initiatives were studied using ethnographic methods during a period of rapid expansion. The concept of self-organisation was operationalised using three dimensions-autonomy, expansion and governance. One initiative established food banks in close cooperation with corporate food actors. Its franchise charity model involved standardised safety protocols and significant centralised control. The other initiative deliberately pursued autonomy, rapid recruitment and de-centralised governance; nevertheless, collaboration with industry actors and a degree of centralised control became a (contested) part of the approach. We highlight the interplay of organisational agency and institutional structures affecting the self-organisation of surplus food redistribution, including ways in which movement dynamism can involve capture by dominant interests but also the seeds of transformative practices that challenge root causes of food waste, particularly food's commodification. Our analysis provides a way to compare the potentials of food charity vs mutual aid in effecting systemic change.
\end{abstract}

Keywords: food waste; food banks; self-organisation; sustainability transitions

\section{Introduction}

\subsection{Surplus Food Redistribution: Managing or Contesting Food System Harms?}

Growing awareness of the environmental and social injustices represented by food waste, and a wish to prevent them, has led to a rapid growth in the number of people engaged in surplus food redistribution initiatives, often mediated by information and communication technology (ICT) [1-3], in what has been termed 'a new era of ICT-mediated food sharing' [4]. However, few studies in the current research literature suggest that the proliferation of such initiatives serves to fundamentally contest-or prevent-over-production or highly inequitable access to food. Our interest in this article is not just in surplus food redistribution as a way of locally addressing food poverty and/or food waste. We are, instead, interested in the potential of surplus food redistribution to contribute to more substantial sustainability transitions. For us, this means structurally addressing the over-production of food and the inequitable distribution of food. This will entail achieving a situation where food producers and food consumers are better able to understand food production networks, and are able to exercise their influence over them not only through price mechanisms, but also in ways that 
enable environmental and social concerns to be more deliberately and more democratically addressed. From this viewpoint, we do not assume that all surplus food redistribution activities potentially contribute to a sustainability transition. On the contrary, simply managing surplus food in order to donate it to food-insecure people may serve to enable business-as-usual rather than contest it. If surplus food redistribution activities are to contribute to a sustainability transition, they will need to challenge the ways that global food production is currently organised. Transforming the over-production of food (and the environmental damage this implies) —and its inequitable distribution-will require movements that do not function as enablers of dominant agri-food dynamics but that contest these discursively, while coordinating efforts to transform distinct food system problems, and the political economies that underlie them. It is the potential to develop such system change that appears to be promised by the concept of self-organisation. We therefore adopt a self-organisation lens to look for evidence of an emerging political repertoire within rapidly growing surplus food redistribution initiatives. Understanding factors affecting the capacity of such initiatives to affect waste-generative conditions, rather than simply manage symptoms, is a key aim of this paper.

\subsection{Self-Organisation and Surplus Food Redistribution}

Within the social and political sciences, self-organisation has traditionally concerned local grass-roots initiatives such as worker-managed factories or community libraries, closely allied to concepts such as mutual aid. This contrasts with understandings of self-organisation in the natural, physical and engineering sciences, where it has been used to describe complex, adaptive, large-scale systems. In recent years, partly resulting from advances in ICT and inspired by cases such as Wikipedia and open-source software development, self-organisation in the social sciences has also started to be applied to social movements and their potential to achieve scale and coordination that arguably mimic systems such as those in colonies of bees and ants or the movement of molecules. In this article we consider two surplus food redistribution initiatives from a self-organisation perspective in order to identify ways in which these initiatives were (self-)organising during the study period and thus might hold the promise of contributing to sustainable transitions in the future [5]. Our guiding questions are thus: to what extent can UK surplus food redistribution initiatives be considered self-organising, and what might this tell us about their potential to challenge systemic causes of food wastage?

We therefore develop a framework for analysis (see Section 2.2 below) from existing literature, which highlights what we take to be key dimensions of self-organisation, namely autonomy, expansion and governance. By examining food redistribution initiatives through these dimensions, we analyse the ways and extent to which they may be considered self-organising, and, thus, to what extent they promise to contribute to sustainability transitions. To do so, we link our schema for recognising self-organisation with concepts from transition theories, especially their emphasis on agency and reflexivity in supporting the transformation of existing food regimes [6,7], and social movement theories, exploring mechanisms by which different methods of contestations impact such shifts [8].

\subsection{Food Redistribution-Two Broad Approaches}

While food redistribution activities are rapidly growing internationally [4], they are far from homogenous, and have often attracted critique. Our paper compares two broad approaches: charitable food banking, and redistribution as mutual aid. Charitable programmes to redistribute food have been contested because of the risk that they do not address structural causes of either over-production [9] or food insecurity $[10,11]$. They have been seen as papering over cracks left by states' withdrawal of statutory welfare provision [12]. Much of the literature analysing activist and charitable forms of surplus food redistribution comes from the experiences of North America, where food banking in particular has spread in recent decades as a means to contain both overproduced food commodities and manage destitution in the context of neoliberal restructuring [13,14]. Poppendieck [10] criticised entrenched food charity in the USA for its inadequacy in solving hunger created by Reagan-era welfare cuts. Such charity, she argued, enabled further state retrenchment by upholding an impression of good 
and capable communities through which the discomfort of living in unequal societies is mollified by well-intentioned acts of voluntarism and donation.

The US food banking system expanded rapidly during the 1980s and 1990s, from dispersed origins that Poppendieck [10] argues were "supply driven", as food surpluses were diverted through the "heroic" and often faith-inspired actions of community members. Poppendieck depicts the "inherent drive toward stability" that saw initial efforts expand into well-resourced logistical networks and formalised food banking organisations. This expansion of corporate-sponsored surplus food redistribution has been analysed in terms of neoliberal governance [14] and the upholding of circuits of capitalist value in economies of manufactured scarcity amid excess [15].

Turning to the UK, 'food poverty' became an increasing concern from the early 2000s [16,17]. The introduction of austerity measures from 2010 intensified discourses around food waste's relationship with food poverty (e.g., Business Ethics Council, 2014). Rapid growth of charitable food provision followed [18], with critical voices noting how such provision lies outside of market functions and state entitlements [12]. The emergence of community self-organisation of charitable food provision was thus problematised as potentially providing a justification for the withdrawal of welfare entitlements [18]. It has also begun to be analysed as part of a globalising spread of the US-originating food bank model $[19,20]$.

Around the world, other efforts to redistribute surplus foods developed more as mutual aid than charity, from the Black Panther Party's alternative provisioning programs created in the face of state neglect in the United States [21] to anarchist-inspired community kitchens [22] and the online food sharing movement that is spreading through mainland Europe from its German origins [23]. A core aim of mutual aid is to provide relief while critiquing unjust economies, with a view to replacing them with systems that satisfy the fundamental food needs of all beings i.e. transforming dominant capitalist production, which proponents have long argued is "obstinately bent on producing more than can possibly be consumed" [24].

Both charity and mutual aid approaches began outside of incumbent institutional arrangements, suggesting impulses towards self-organisation and the potential to effect sustainability transitions [25]. However, contextual and ideological differences underlie the tendency towards food banking's maintenance of existing food regimes, while mutual aid seeks to transform these. We will therefore analyse the nature and extent of self-organisation in two UK initiatives, one that is closer to the US-style charitable foodbank model, and another that attempts a more distanced and critical relation to established food industry actors.

\subsection{Aim and Contribution}

The aim of this paper is to ask whether, by examining existing surplus food redistribution initiatives from a self-organisation viewpoint, we can find evidence that they have the potential to significantly impact the problems they claim to address. To this end, we examine two UK cases that represent two broad approaches amongst contemporary food redistribution initiatives, and analyse them in terms of three dimensions of self-organisation: autonomy, expansion and governance. Our contribution is conceptual and empirical. Conceptually our operationalisation of self-organisation (through the dimensions of autonomy, expansion and governance) usefully grounds the concept and counters the tendency for it to become a hollow buzzword, while also linking it to developments in transition-oriented research into mechanisms for transformative system change. Empirically, the cases presented, in different ways and to different extents, struggle to move beyond the immediate challenges of redistributing surplus food to the more intractable political challenge of contesting the over-production and inequitable distribution of food. A longer time frame and a broader selection of cases will be required to draw firmer conclusions. 


\section{Materials and Methods}

\subsection{Description of Cases}

The two UK initiatives researched for this paper, a national surplus food redistribution charity and a network of surplus food cafés, represent contrasting logics and implications of self-organisation for transitioning to less wasteful and more socially just food systems. The organisations have been given pseudonyms.

\subsubsection{National Charity}

The National Charity operates on a franchise basis from headquarters in London. The north England franchise where this research took place is housed and managed by a social enterprise which specialises in recycling. The National Charity's model of operation resembles American-style food banking: networked warehousing and logistics for managing and charitably redistributing large quantities of industrial surplus food. The charity is coordinated at the national level and engages suppliers (primarily major retailers), who supply surplus food to regional franchises. These receive, store and redistribute food, for a fee, to local community groups, schools and voluntary sector bodies. The Charity's recent rapid growth mirrors the expansion of UK food charities more broadly in response to growing levels of food insecurity [12] as well as increasing problematisations of food wastage. In recent years, the Charity has partnered with a social enterprise to enable local charities to access surplus food directly from retail stores, using mobile app technology [26].

\subsubsection{SurplusCafé Network}

SurplusCafé was founded in 2013, initially with a café in a city in northern England, and claims to have inspired over 120 projects in seven countries. Some co-founders were previously engaged in 'dumpster-diving' (or 'skipping', as it is more commonly termed in the UK), which had taught them how to source, 'intercept', and utilise discarded foods [27]. Eating wasted foods is one strand of 'freegan' praxis [28]; freegans opt to make use of under-utilised resources such as empty housing or discarded foods, expressing a lived critique of capitalist wastefulness [29]. Another co-founder had returned from travels in Australia where he witnessed surplus food being fed to pigs and was determined to feed people with wasted food once he returned home.

Both the National Charity and SurplusCafé network emerged from pre-existing institutional and discursive landscapes, including UK and US histories and cultures of charitable responses to poverty, and a growing tendency for food corporations to seek community-based solutions to the reputational threats and management challenges presented by public problematisations of food waste. This context foregrounds our analysis of these cases as examples of self-organisation in terms of autonomy, growth and governance.

\subsection{Data-Collection and Analysis}

This article draws on ethnographic field research carried out by the lead author between 2015 and 2017, consisting of 14 days of participant observation at one of the National Charity's north England franchises and interviews with six staff members, plus 15 days of participant observation at SurplusCafés across the UK (including attendance of two Annual General Meetings (AGMs)) and interviews with 19 of the network's organisers (see also Spring, 2018). Participant observation enabled the author to ground their understanding of everyday practices and spatial-material contexts over time, as well as some triangulation of interviews. Detailed fieldnotes were kept and compared to interview data during an iterative, abductive coding process. In order to understand the nature and extent of the self-organisation characterising the two case organisations, ethnographic data was analysed initial open-coding of data as part of a wider doctoral project. Having derived our three analytical dimensions (autonomy, expansion, and governance) from the literature, a second stage of thematic coding (using NVivo 11 software) was undertaken. We found it useful to refer to the sustainability 
transition literature below, as our conceptualisation of self-organisation resonates in a number of ways with analyses of 'social innovation', another term with broad and potentially divergent appeal [30]. The following sub-sections explain further the three dimensions of self-organisation through which we organise our analysis.

\subsubsection{Dimension of Self-Organisation 1: Autonomy}

There is a strong expectation in the literature that self-organisation should emerge bottom-up from within communities, and not as something commissioned by outsiders [31]. The sustainability transition literature has examined the transformative potential of civil society organisations that, "by virtue of being positioned outside of industrial regimes, are of prime importance in the societal reorientation of incumbent socio-technical systems of provision towards sustainability" [25]. However, this 'outside' is nevertheless defined and shaped by existing dominant arrangements. Fuchs' [8] discussion of self-organisation in social movements implies that, even in theory, autonomous organisation may be difficult to envisage. In this view, social movements are interposed between the concrete realities of the world as it is, and the possibilities of a better future; they are therefore always centred on a form of protest, yet are always to some degree shaped by existing social structures. Self-organisation is never wholly alternative to, and separate from, existing realities. Importantly, it may reproduce or be captured by extant/dominant interests. Pel and Bauler [30] observe how social innovations often follow a "dialectical process in which transformative moments and capture alternate". How, then, might innovations not simply respond to meet immediate needs but also resist co-optation and change social relations?

In practice, the wide currency that the idea of self-organisation has gained has paradoxically led to situations where it is more likely to be commissioned and less likely to be wholly bottom-up and autonomous. External actors have looked to promote self-organisation in communities; this may partly be ideologically motivated as officials are inspired by its potential [32], but it may also be a strategic response to austerity and the withdrawal of public welfare services [33]. Thus, government bodies, who one might expect to be threatened by self-organised movements seeking radical change, have, on the contrary, been actively seeking to bring them into being [32,34]. In the specific case of food redistribution activities, there is a particular paradox, as activities are dependent on the problem (food waste) that they are seeking to prevent and on achieving a collaboration with the actors (food corporations and state regulators) whose behaviour and motivations need to change if food systems are to transition.

It is therefore essential to ask to what extent a 'self-organised' movement is able to act autonomously. Our analysis considers the extent and ways in which food redistribution initiatives originate in, or become coopted by, existing structures, and the extent to which such relationships compromise their claims of self-organisation, and, importantly, constrain their capacity for transformative change.

\subsubsection{Dimension of Self-Organisation 2: Expansion}

Much of the logic of self-organisation in natural and physical sciences, and much of the attraction of the concept in a social science setting, relates to very large and complex systems [32,35]. Food redistribution activities (collection of surplus food from supermarkets and other sources, sometimes sorting/preparing, and delivery to recipients), involve local relationships and coordination. In terms of physical mobility and social engagement, the initial requirements are greater than those of (for example) editing Wikipedia articles [32]: the material and temporal specificities of food require investment in spatial infrastructures as well as adequate labour to responsibly effect its redistribution. Expansion requires some kind of coordination not only within these place-based redistribution communities, but also coordination between different communities in the same city/region, and also with other cities/regions. However, expansion is not without risks. Standardisation and the creation of digital platforms to enable expansion has created opportunities for corporate actors to exercise key 
control, so that while an organisation may retain autonomy and resist regulation, this may serve the interests of a corporate sponsor rather than of members or participants $[6,26,36,37]$.

Our analysis will therefore examine the extent to which initiatives have low entry barriers and enable the rapid incorporation of actors whose motivations are in tune with the organisation, and the extent to which any rapid expansion compromises the overall orientation of the initiative, which relates to the final dimension of governance.

\subsubsection{Dimension of Self-Organisation 3: Governance}

Self-organisation goes hand in hand with ideas of decentralisation. Self-organised systems and movements are coherent, are able to learn, but are not centrally controlled:

A self-organising system functions without central control, and through contextual local interactions. Components achieve a simple task individually, but a complex collective behaviour emerges from their mutual interactions. Such a system modifies its structure and functionality to adapt to changes to requirements and to the environment based on previous experience. Nature provides examples of self-organisation, such as ants food foraging, molecule formation, or antibodies detection. [35]

In human settings such emergence is a more relative (and political) question; some degree of conscious control or coordination will be required. So the question is not necessarily of movements functioning "without central control" but rather of mechanisms to enable local adaptation and initiatives, democratic accountability and overall system flexibility and the capacity to learn [8]. The emphasis on adaptation and learning is particularly important in the context of global food networks which are notoriously opaque and where power is unevenly distributed between producers, intermediaries and consumers. Rapidly growing, effective social movements do not only need to adapt to the differing interests and situations of their members, but also to the unfolding strategies and resistance of opponents, not least the capital-rich, internationally networked corporations whose ways of operating they will ultimately need to challenge and change. The literature on self-organisation therefore focuses on mechanisms (such as protocols), and on forms of decentralisation that enable learning to accumulate without central processing [38,39].

This quest for strategic and distributed leadership, compatible with self-organisation, is often discussed in terms of 'self-governance' $[40,41]$. Concepts of 'emergence' and 'co-evolution' in sustainability transition theorisations also express this recursivity between bottom-up agency (and internal differentiation) and top-down governance [5]. Such literature highlights the importance of reflexive governance, i.e., the role of self-confrontation and learning in achieving more distributed and democratic forms of organisation [7]. Discursive reflexivity plays a vital role in achieving a broad, contestatory movement capable of allying different movement actors and posing a significant challenge to incumbent arrangements. Attending to meaning-making through discourse was thus an important part of our fieldwork and analysis. If self-organisation reflects a dialectical interplay of agency and structure [8], then attending to the ways redistribution organisations articulate their visions and processes-internally and publicly—can shed light on the likelihood of innovations growing beyond their initial niche [42]. We will thus examine how organisations learn, develop, and communicate. To what extent does this enable local branches and individual members to participate not only in the physical labour of redistribution, but also in broader, more reflexive processes of governing the initiative towards potentially more transformative goals?

\section{Results}

This section considers each type of redistribution organisation according to the dimensions of self-organisation identified in the previous section. 


\subsection{Autonomy}

This section analyses to what extent each organisation was initiated and steered by a community of activists rather than by external state or corporate sponsors, by examining their origins and founding aims.

\subsubsection{Autonomy: National Charity}

The National Charity was co-founded in 1994 by a homelessness charity and a major grocery retailer to divert healthy surplus food to homeless people. Enacting the discursive and practical problematisation of food wastage alongside food insecurity, it thus began as a formalised partnership between existing institutional actors [43]. Food surplus was treated as a resource that could help to alleviate nutritional deficiencies, rather than as an indicator of deeper food system problems. One manager drew on her decades of charitable employment to imply that, while demand for food charity has persisted, certain underlying causes of that need also persist:

... we were dishing out free sandwiches in 1986 to play scheme kids and now in 2016 you're still dishing out food to people in need and you wonder what's changed for the better... (Manager, Interview 11/02/2016)

The National Charity's founding rationale in the waste management concerns of a major retailer suggests a self-initiated response to perceived market failures by commercial actors, who may also benefit reputationally from partnering with non-profit organisations that highlight and/or protest the contradictions of wastage alongside hunger. The charity has since become part of global networks of food banks whose origins draw from similar circumstances: high levels of corporate surplus, growing social inequality and communities' desires to redress 'hunger' [10]. While most upscaled charitable food redistribution organisations originated as small civil society-initiated efforts [44], these have often developed collaborative sponsorships and partnerships with corporate and state actors in their effort to grow [14]. The extent to which compliance relations within the National Charity's franchise structure and corporate donor relations limit its capacity to act autonomously are further explored in Section 3.3.1 (Governance).

\subsubsection{Autonomy: SurplusCafé}

Following its founding in 2014, the first pay-as-you-feel SurplusCafé was soon collecting mounting quantities of food, attracting volunteers, and providing meals to a growing clientele. It felt innovative: one co-founder described the "slightly chaotic starting-up of a project in an area where we didn't see another café or something similar where we could say 'look, they've done it, we can do this'" (Interview, 21/03/2017). They were unsure, for example, whether to communicate to clients the provenance of the food, as food redistribution was not yet a widely accepted practice. Thus, SurplusCafé's founders felt they were enacting a unique response to the perceived profligacy of food retail, as well as high levels of destitution. At first, most food was acquired through skipping, meaning relative independence from donor expectations or conditions, but a co-founder described the practical challenges of this:

... you really don't know what you're gonna get and you've got to go out at night, drive like 10 miles out of [the city], spend 45 min going through bins, get all the food back, wash it... (Interview, 21/03/2017)

As the network gained exposure, major food industry actors contacted SurplusCafé to donate products, which entailed new challenges of food management, but which also impacted organisers' capacity to act autonomously, as explored further in Section 3.2.2 (Expansion).

These origins suggest the grassroots emergence of self-organisation from more disparate practices of dumpster-diving. Like the Charity, SurplusCafé grew from the founders' navigation of moral contradictions of waste amid poverty. However, its roots in the ethics of freeganism [27], plus 
its stated desire to address systemic injustice rather than simply 'manage' symptomatic problems, shaped its approach. The SurplusCafé Network aimed to make food available to anyone through its pay-as-you-feel café model, hoping to challenge root causes of food wastage-and envisage alternatives-whilst avoiding the conditionalities and corporate obeisance many organisers feel characterise charitable food banking. One organiser explained her preference for the SurplusCafé model:

... Everyone was going 'ooh, I've given a box of biscuits to the foodbank [via in-store donation point] and now I'm feeling really good about it' and I was thinking 'but that is not right-so Tesco are making money out of you buying biscuits which you're giving to the foodbank which makes you feel good'-this is not what hunger is about! (Interview, SurplusCafé organiser, 3/8/2016)

Most SurplusCafé organisers thus envisaged building a more radical alternative to what they saw as shortcomings in the dominant models of food redistribution, enacting mutual aid in vociferous contrast to being identified as charity.

\subsection{Expansion}

This section explores the extent to which low-entry thresholds enabled the rapid recruitment of individuals committed to the organisation's overall goals. Did increased coordination and growth compromise its founding aims and values?

\subsubsection{Expansion: The National Charity}

The Charity grew relatively slowly during its first two decades. By the time of research, however, it was seeking to expand rapidly:

... our aim as a network of 21 depots is to handle and receive $25 \%$ of the UK's edible surplus in 5 years' time. We're at $2 \%$ at the moment, so that's our main project ... (Interview, Manager, $11 / 02 / 2016)$

It was also soliciting private donors for financial support, generating a sense of urgency:

... change is happening, quicker than they've ever seen it ... Double the membership, double the volunteers, bang bang. And it's gotta happen quickly, cause that's why they're giving us the money. (Interview, Manager, 4/11/2015)

The large warehouses required to handle significant donations of food, and the heavy compliance requirements placed on these physical spaces and their management, have meant slower growth than SurplusCafé's disparate café openings, but the resulting infrastructure comprises a more permanent, high-turnover operation. Such upscaled infrastructure relies upon external funding and is unlikely to occur organically through the expanding volunteer base and localised affordances that enabled the SurplusCafé network to grow. For one thing, compliance requirements issued from corporate donors necessitate volunteer management that, for the franchise in question, required further fundraising, training and new recruitment channels. Expansion also required the charity to increase connections locally with subscribing organisations who could receive (and pay for) food:

In the last financial year we gave out about 550 tonnes of food so we're looking to ... double our output this year. And then continue. So to be able to do that we obviously need the supplies but need to have the places to distribute to, so it's a really important partnership between us and the communities, otherwise we can't do it- we end up throwing it away. (Interview, Manager, 11/02/2016)

The Charity had long received forms of state support (e.g., some new recipient organisations were supported to receive surplus food by local authorities funding short-term subscriptions). However, following significant expansion amidst growing public awareness of food waste and food insecurity, in 2018, the Charity launched an online petition for government subsidies to incentivise redistribution for 
human consumption. The Charity also receives significant corporate sponsorship, through in-kind agreements with retailers, and its membership of the Global FoodBanking Network (GFN), which funnels donations from major industrial actors to support the infrastructural rollout of food banking [19]. The GFN's annual conference in the UK in 2019 highlighted the international expansion of this model of food banking from its North American origins [19,45]. Support and influence from these corporate food industry actors complicate any idea of the charity as self-organising from the grassroots.

A 2000 report foresaw conditions favourable to the growth of UK surplus food redistribution, including tightening local authority budgets and governmental encouragement of "voluntary sector-corporate, and private-public links" in service provision [46]. Compliance with industry norms was one feature of its growth: "NGO innovation in North America had paved the way for large-scale food banking through fostering "trustworthiness in food safety and security issues" [46]. Enacting such compliance is a key part of the National Charity's relationships with donors [9], protecting industrial actors from prosecution and upholding reputability, but also entailing high entry barriers for new franchises-hence the Charity's focus on expanding individual franchises and their logistical capacity to serve regional hinterlands.

\subsubsection{Expansion: SurplusCafé}

The SurplusCafé network grew from its flagship café in early 2014 to reportedly over 100 cafés by early 2019. In March 2014, The Guardian newspaper uploaded a film about the project, sparking a welter of attention and growth: "we had 100,000 hits in 48 hours", a founder recalled at the 2015 network AGM. People around the world sent messages asking for help in setting up SurplusCafés: the founder saw this as a chance to "empower and inspire these people". Rather than setting up new cafés themselves, the network provided a model that others could adopt.

Increasing attention came from food suppliers hoping to donate surpluses, from end-of-day sandwiches donated by nearby cafés to a multinational dairy distributor providing hundreds of litres of cream. A highly publicised 2016 television documentary about food waste, presented by celebrity chef Hugh Fearnley-Whittingstall, also prompted supply offers. While previously they had struggled to obtain enough food, now they faced a new problem of obtaining the labour and infrastructure to utilise so much food. The question also emerged of how to sustain the largely unpaid labour of running cafés once initial enthusiasm began to wane, prompting conflicting ideas. One café aimed "to build a kind of community around our volunteers", envisaging the resulting networks as future arbiters of localised self-sufficiency through food growing and voluntarism, rather than simply "moving food waste around" (Interview, SurplusCafé organiser, 09/11/2015). They thus viewed volunteers as members of a future-oriented strategy for system transformation, beyond collecting food and feeding people. Other organisers, meanwhile, felt that feeding people was enough, especially in places experiencing high levels of food insecurity; the challenges and affordances of different geographies thus shaped localised responses.

Digital means of enrolling and communicating with café clients and volunteers included Facebook Pages maintained by individual SurplusCafés: posting daily menus, attracting volunteers and sometimes providing a forum to discuss issues like pay-as-you-feel behaviours or the role of expiry-date labels. One organiser observed that some volunteers did not have mobile phones or internet access, necessitating a diversity of communication approaches. Most cafés were listed in a directory on the central SurplusCafé website. Media exposure and social media platforms undoubtedly accelerated SurplusCafé's profile and workload.

However, growth sometimes sat uncomfortably alongside the founder's oft-repeated intention to 'put ourselves out of business' by preventing food wastage. This contradiction resurfaced in organisers' efforts to secure food [47]. The central network did not impose strict rules for how individual SurplusCafés should access wasted food. 'Skipping', once the initial thrill had ebbed, was often described as tiring, dirty and disappointing if bins were locked or empty. Some cafés opted to use digital platforms such as FoodCloud and Neighbourly to collect food supplies from supermarkets. 
These involved certain limitations, including temporal and logistical mismatches between retailers disposing of food and organisers' capacities to collect and use it. Some SurplusCafés received food from the National Charity, highlighting (to some organisers) the two intiatives' divergent values:

[The charity] has a completely different ethos to [SurplusCafé]. I think they just want to gather as much food as they can to say it's rescued... Thursday about 12 o'clock they delivered 240 bags of leaves, knowing that we were closing in two hours... If you can't get rid of it, it's your waste, I'm not having it ... (Interview, SurplusCafé organiser, 3/8/2016)

This quote suggests how both organisations were made responsible for absorbing large quantities of industry surplus. However, some SurplusCafé organisers accused the National Charity of expanding without addressing systemic causes of food waste, while celebrating industrial donors on social media [48]. In contrast, several SurplusCafé organisers used social media as a protest tool to expose the limitations of supermarkets' growing efforts to formally donate edible surpluses. Establishing formal relationships with industry donors was described as a mixed blessing, with some SurplusCafé organisers feeling that only a small proportion of low-risk food was being donated so that retailers could benefit reputationally.

Despite these perceived differences in praxis, a key growth challenge was securing outlets for intercepted food (as for the National Charity). Many cafés placed excess food in "food boutiques" (a play on 'food bank' but purposively lacking the conditionalities for access for which organisers sometimes criticised charity models): freely-accessible tables or cupboards, for which café visitors could pay as they felt. Upscaling further, some SurplusCafés opened warehouses where visitors could 'shop' for a bigger range of surplus foods. Others partnered with schools to set up playground marketplaces for surplus food, partly to educate students in waste prevention, but also to secure outlets for food and a steadier income [49].

As with the National Charity, growth was limited by material-spatial factors. Accessing spaces, equipment and regulatory advice was essential for growth but frequently precarious. Some projects were limited in their capacity due to having no permanent premises, borrowing church or university kitchens on specific days. Their community-oriented aims enabled some to acquire resources for free. Debates arose about how to formalise support for new cafés, such as through inter-café loans, but one organiser noted that not all such processes could remain informal and would require formal accounting and application procedures. A charitable trust and board was set up to manage governance as the network grew, described by one trustee as a way to balance the founder's blue-sky thinking and 'can-do' experiments with processes to ensure accountability and consistency through engaging trustees with the requisite skills and motivations. Nevertheless, she expressed her pride in the decentralised structure of the growing network, bringing us to the theme of governance:

We're a network of cells, we're Zapatistas- that's what we're doing! And I just love it. 'Cause you can't wipe us out-if you find one of us, you'll never get us all! (Interview, SurplusCafé organiser, 16/01/2016)

\subsection{Governance}

This section explores the extent to which coherent and coordinated action was achieved by the two initiatives without strongly centralised command and control.

\subsubsection{Governance and Adaptation: The National Charity}

The Charity's franchise structure aims to preserve the localised character of its member franchises, while providing a central function for fundraising, managing industry donation/compliance relations and other administrative and public relations matters. Some functions remain more centralised than others. The franchise member in our study was managing unpredictable daily food deliveries both inwards and outwards, attempting to coordinate these with recipient organisations' needs and a 
precarious, largely volunteer workforce. Daily concerns for franchises often differed from the central charity's prerogatives; for example, while the central charity did not have an explicit policy or staff member campaigning against food insecurity, some franchise staff were partnering with a 'food poverty alliance' to engage with growing local concern around hunger.

An exception to these localised functions was the management of food safety. The National Charity imposes a more rigid codification of logistical behaviours and processes to its member franchises than SurplusCafé. All franchises must adhere to a centrally maintained food safety manual and undergo forms of monitoring such as receiving visits from contractors who check temperature controls, etc. However, franchises take responsibility for managing these standards among their workforce and end-recipients. New volunteers undertake formal training in topics including food hygiene. Organisations receiving food are expected to meet certain handling standards. Volunteers delivering orders would occasionally report back to the Charity depot if they felt a recipient organisation was not compliant. The importance of food safety, functioning both to ensure adequate food for eventual eaters and to appease donors [13], was thus a value shared throughout the Charity, embedded in everyday workplace practices and managed through significant paperwork and mutual surveillance.

Volunteers and managers developed face-to-face relationships with food recipients, often at the warehouse door as clients waited for their food orders. Staff attempted to learn from them and respond to their needs. However, at an organisational level, centralised management and compliance regimes mitigate against the sort of localised learning and flexible responses that are associated with self-organisation in other fields [39].

\subsubsection{Governance and Adaptation: SurplusCafé}

While using surplus food and 'pay-as-you-feel' formed the core of the SurplusCafé model, cafés often differed significantly in their main motivations and practices, including relationships with donors. An organiser described how a SurplusCafé in a deprived housing estate was "bridging that gap between some food and no food", while an affluent town-centre SurplusCafé was "demonstrating how very edible food waste is" (Interview, 18/01/2016). Another organiser aimed to provide asylum seekers a safe and affordable place to have coffee and meet others. SurplusCafés often reflected the particularities of their venues, geographies and, sometimes, political affiliations (e.g., serving curries at political demonstrations).

Digital communications provided one means of maintaining the network's identity in the midst of this diversity and geographical dispersion. One SurplusCafé organiser 'liked' the flagship café on Facebook and, upon visiting to enquire about setting up her own, recalls the excitement of feeling "part of a movement". She felt supported but able to develop independently. She described:

... that fabulous balance of 'get on with it, do it yourself, I'm not gonna hold your hand but of course I'm there if you need me'... And I have called [founder] at moments or I've put on the WhatsApp group, "Help!", or whatever. But we are an independent Community Interest Company; we say 'part of [SurplusCafé]', it's on our signage outside, on the website, we put it out there but legally binding on paper, there's no definite contractual relationship there. (Interview, 7/12/16)

Each café adopted distinct governance forms—-some registered as social enterprises, others were subsidiaries of existing charities or institutions (e.g., churches). Asked about network membership rules, one organiser said that, aside from using pay-as-you-feel and the requirement to use a certain percentage of surplus food, "there was this long list of rules and regulations ... that they emailed through to us and we were like 'what? We don't wanna sign up to all of this' but it doesn't really mean anything ... things like the food bank being called a food boutique" (Interview, 24/06/2016). Cafés thus adopted tighter adherence to some 'rules' than others, with online communications and face-to-face meetings providing ways to share challenges and ideas.

A SurplusCafé founder formed a charitable trust to try to balance the informal serendipity and formal organising that many felt was required as the network grew. For example, café organisers were 
expected to measure and communicate data about 'intercepted' food quantities to the central trust, believed to be important in furthering SurplusCafé's campaigning goals in order to raise awareness of wastage. However, this entailed additional daily labour and some organisers expressed confusion around the purpose and impacts of providing such data, suggesting shortcomings in how overall goals were communicated and linked with local practices and the requirements placed on individual SurplusCafés by the central network.

Some organisers noted governance challenges related to intra-city expansion, such as how new SurplusCafés would relate to existing café projects in their wider (e.g., city/regional) geographies:

... we're not intending to run all of the cafés ourselves- that's really important I think. I mean, what we've found with some of the cafés we've been running is that these are really hyper-local community organisations and it's really important to have real engagement from the local community and to have volunteers from the local community front and centre at the café helps with that engagement, so you know we're not looking to run round [the city] running lots of cafés... (Interview, 09/11/2015)

Conflicts did emerge over organisational praxis, such as one organiser who felt that the existing operating model could not deliver the wider movement goal of "abolishing food waste". At the 2016 AGM he used a pan of rice to demonstrate that UK food supplies far outstrip its caloric needs; simply "moving the food waste around" would not address root causes of overproduction and corporate control. He announced:

What we're defining as the problems are actually symptoms- the food waste that we're seeing every day is a symptom of the problems in our food systems at the moment- the core problem is oversupply and that's about the fact that very few actors in that system, control the system.

His suggested solution was to ally with the UK food sovereignty movement to address major questions of agrifood policy, whilst building networks of volunteers who could nurture credible alternatives to dominant food systems, e.g., through urban growth. After three years of operation, the members of his city's network held conflicting concerns about more ecological versus community-oriented goals. Conflicts emerged over degrees of formalisation deemed appropriate, such as one volunteer taking over management of the 'food boutique' which was previously unstaffed but which now was staffed, with donations recorded. These perceived mission drifts from the anarchistic founding ethos led to this organiser's departure. Other café projects have since become independent from the SurplusCafé network-for example, one opened a kitchen for refugees in Greece, while others re-branded as independent organisations (who often still draw on the friendship and networks formed in the early stages, however).

\section{Discussion}

\subsection{Contrasting Logics of Redistribution}

The two initiatives represent contrasting organisational tendencies of the food redistribution movement. Large food redistribution charities are often part of, or linked to, industry-founded 'corporate social responsibility' initiatives and are therefore less concerned with fostering alternatives to existing market/state arrangements. Food banking, itself originating as a grassroots response in 1960s America, functions as a dramatically rescaled, globalised containment of retail surpluses produced by the concentration and consolidation of global retail capital in the late 20th century [50]. As such, it is unsurprising that the National Charity, as a member of the Global FoodBanking Network, meets fewer of the expectations of self-organisation assumed by our framework (grassroots origins, rapid growth, flexible governance). State and market actors have supported the National Charity's growth through, e.g., grants for logistics, suggesting a top-down sponsorship role for what is frequently perceived as, and enabled by, grassroots labour and 'community' agency [32]. Reflecting incumbent interests, it 
neither demands nor promises to deliver the regime shifts that would characterise transitions towards greater socio-ecological sustainability.

By contrast, SurplusCafé's rootedness in discourses of freeganism and social justice shaped its efforts to maintain discursive and material distance from corporate food actors. SurplusCafé explicitly aimed to be an autonomous, self-governed movement as it expanded, ultimately hoping to engender alternatives to waste-generating institutions. However, unavoidable collaboration with waste-generating food businesses in order to run its cafés constrained the movement's autonomy, emphasising the typical contradictions and conflicts that arise from initiatives that seek both system (process) changes, yet meet immediate needs through programmes that are dependent on receiving food that would otherwise have been wasted [30]. Importantly, it must be borne in mind that both organisations were addressing the visceral existence of not only excessive food flows, but people struggling to access adequate diets. Their interests in maintaining food flows was never solely about raising revenue (to pay staff, expand and so on), and members of both organisations expressed an intention to 'not have to exist', but many felt equally compelled to continue work for which they saw a persistent need.

Our findings outlined the factors behind SurplusCafé's growth, including media attention, adaptations to the labour and logistical demands of redistributing surplus food, and relationships with various actors locally and on a larger scale. A proliferating network entailed increasingly complex relationships between cafés, donors, volunteers, regulators and other institutions, requiring new structures of self-management. Unlike the National Charity's explicit growth targets (and lobbying for government support to enable this), most SurplusCafé organisers expressed ambiguity around the implications of rapid growth for the overall aims of 'doing ourselves out of business'. New challenges arose-how to pay wages, find and maintain premises, secure increasing food inflows and outflows, and so on, limiting time for reflection, strategising and forming alliances. SurplusCafé represented itself to the outside world via traditional media and maintaining various digital presences. Its governance involved a wide array of volunteers, eaters, donors and other bodies, requiring a diversity of informal and dispersed governance arrangements that allow for experimentation, but might prevent transitions to a coherent voice able to challenge existing power arrangements. Nevertheless, the reflexivity evident in its internal debates, and its often-contestatory external messaging, suggest a more politicised process of change and agential orientation towards more fundamental transitions (which, nevertheless, at times revealed the strictures of relying upon industrial donors, and even led to internal fragmentation).

\subsection{Codifying Food Safety: Balancing Innovation and Liability}

Expansion entails new governance challenges, which may involve a shift away from initial goals. For example, in contrast to SurplusCafé's somewhat haphazard attraction of donors, the National Charity's slower growth as a franchise allowed for the development of a codified protocol for managing food safely, reassuring retailers that new regional franchises would have the knowledge and networks to be trusted in handling their surpluses. Through the lens of food safety governance, and in the context of a diminished welfare state and resurgent food philanthropy, food insecurity and food access are thus shaped by corporate compliance concerns that manifest as conditionalities for eventual eaters (requiring specific behaviours and techniques that would not be required of people purchasing food through 'normal' channels, i.e., shopping). Balancing food safety, food waste and food insecurity concerns is a theme raised elsewhere in the literature [51,52], but our analysis suggests that formalised charity governance involves a codification of standards that seeks to maintain incumbent institutional relations, rather than to build decentralised capacity for the experimentation expected of self-organisation. Rather than an expanding grassroots movement aided by digital networks, the expansion of food banking, of which the National Charity plays a part, results from broader shifts in agrifood governance, state retrenchment and the reassertion of non-market/state actors in the provision of basic requirements for life [14]. 


\subsection{Discursive Contestation and Limits on Transformative Potential}

We noted earlier the importance of attending to meaning-making processes in the reflexive efforts of self-organising movements to effect value-based social change. Popular public discourses around the 'win-win' desirability of using food surpluses to alleviate hunger [43] might help explain SurplusCafé's struggles to articulate a transformative political vision, given how surplus redistribution was celebrated and welcomed in these new spaces of commensality and voluntarism. The Charity also benefitted from-and helped to shape-such discourses, which spurred policy attention and material resources, enabling further expansion ("double our output").

We considered SurplusCafé's internal contestations around the transformative potentials of redistribution. The opening of warehouse-scale 'anti-supermarkets', for example, attempted to provide an upscaled, viable alternative to regular grocery shopping, but still relied upon accessing adequate sources of surplus, and led to conflict with regulators rather than support and/or transformation of incumbent regulatory regimes. Other organisers, concerned about replicating charitable food banking, articulated alternative solutions, such as embracing food sovereignty and building local food webs as a means to galvanise transformative provisioning systems. However, these articulations did not come to characterise the wider organisation, reliant as it remained on the prime task of utilising surpluses (though many organisers felt that such transformations should, at least, constitute the longer-term goal).

These tendencies towards diversification and networking suggest a broadened notion of the 'self' in 'self-organisation'; while exerting agency, most organisers realised that they could not break the existing pathways alone [42]. At the same time, most SurplusCafés developed their service provision through expanding donor and recipient bases rather than focusing strategically on the difficult task of building political partnerships. Added to the sense by some organisers that governance structures were not as participatory and flexible as they had previously perceived, SurplusCafé lost some network members and struggled to build a broader constellation of cooperation with transformative food movements.

\subsection{Interactions between Origins, Growth and Governance in Effecting Transformative Change}

Despite its rootedness in the "countercultural labours" of activists the globe over, intercepting and repurposing discarded foods to enact "alternative visions of an urban, globalised future" [53], tracing SurplusCafé's journey through our three-part analysis of self-organisation, highlights factors affecting the emergence of potentially transformative patterns from its relative autonomy, loosely structured expansion and governance. Its originating concept attracted interest from schools, food businesses and other interests. It inspired a diverse array of people to organise around intercepting and utilising wasted food. However, expansion required governing increasingly complex projects: raising and managing funds, tensions between the reliance upon and contestation of dominant food systems, and managing diverse opinions around organisational priorities. While informal digital networks allowed for information exchange and mutual support, uncertainty around codified rules as well as conflicts over resource management and governance acted to disperse rather than strengthen SurplusCafé's mobilisations to counter food wastage.

A more optimistic interpretation of SurplusCafé's partial dispersal might be seen as a process of reflexive co-evolution, whereby different actors and their interactions shape, but do not determine, overall outcomes [7]. Similarly, self-organisation theory emphasises emergence and a recursive, fluid relationship between wholes and parts in ways that cannot be determined by a single leader or decision in time [8]. Movements like SurplusCafé can thus be conceptualised as ever-shifting assemblages of people, places, technologies, laws and so on. Constituent parts may cohere at times, and at others act in a dispersed fashion, with potentially emergent properties, as [54] argue of popular democratic uprisings post-2011. The experimental ethos and diverse values within the SurplusCafé network ultimately conflicted with an perceived shift for some organisers towards less participatory and more centralised governance. Nevertheless, dispersal arguably also enabled projects to adapt to new contexts and try new approaches. For example, after splitting from the network, one project decided to bid for a 
central government fund for upscaling redistribution. This may not have fitted with the central ethos of SurplusCafé, but it resulted in a suite of knowledge about the opportunities and conditionalities of such grant funding. Reflexive governance that tends to be to experimental and potentially dispersal, in other words, can result in greater autonomy, with the potential for further emergent effects.

This leads us to examine our three-dimensional frame in terms of synergies and trade-offs between dimensions. Autonomy alone is insufficient to guarantee that participants in socially innovative initiatives will choose a radical path. Ideally, autonomy would allow an initiative to achieve sufficient discretionary power to develop a political programme (whether at local, national or other levels), which is not dependent on the approval and/or sponsorship of business-as-usual actors. In relation to our point about the pressing need to address hunger in communities, it must be acknowledged that many of those interacting with surplus redistribution organisations may, understandably, be motivated more by companionship and affordable food than by a vision for an alternative society. Creating spaces for community participation and engagement with issues, as was often the case during sessions of cooking and eating in SurplusCafés, may provide an infrastructure for other kinds of politicised participation.

The creation of autonomous spaces must be made available to greater numbers of people, hence the need to examine the dynamics of expansion for self-organisation to become a politically transitional force, by creating conditions to include enough engaged members to constitute some form of critical mass in terms of achieving change. Governance can be seen as the bridge between autonomous origins and expansion. It should take a form that enables the vision developed by the relatively autonomous organisation to continue to invigorate, and be invigorated by, a rapidly growing membership/movement. Where growing visibility and membership requires greater reliance on corporate actors, and less participatory governance, we see how the dynamics of self-organisation may involve trade-offs.

The stakes are high for the kind of systemic change envisioned by SurplusCafé, which would represent a major challenge to supermarket dominance and a reconfiguration of consumer relationships with food (towards greater reckoning with use values, for example). The problems of food waste and food insecurity are deeply rooted in extant food and economic systems. Analysing any effort to transform these must bear this in mind; both are not aberrations of otherwise-functioning realities but are the result of "flawed, relatively accidental institutional arrangements" [55]. When discussing the capacity for self-organising social movements to effect justice-oriented transitions, we must also recognise that dominant interests in a neoliberal age themselves adopt aspects of self-organisation: decentralised networking, global telecommunications and horizontal restructuring have become key tools for capital accumulation by business [8]. The risks of cooptation and mission drift of initiatives with radical roots and intentions are suggested by SurplusCafé's trajectory, [e.g. 51] note that supermarkets and other entrepreneurial ventures have begun to commoditise surplus foods themselves. However, the central network, comprised by an ever-changing constellation of constituent members, was enacting forms of experimental provisioning and seeds of discursive transformation, reflected perhaps that by the end of the fieldwork period, SurplusCafé was widely known about and had perhaps spawned the generic notion of a 'pay-as-you-feel café' with a range of community functions that went beyond alleviating food waste and food insecurity [56].

\section{Conclusions}

In the sustainable transition literature, social innovation is transformative to the extent that it challenges, alters and/or replaces dominant institutions [57]. Like socially innovative ideas and discourses, self-organising initiatives can be easily coopted by dominant interests. Our analysis provides a way to assess evidence of self-organisation, as a boundary concept that risks becoming a buzzword; however, it is hoped that this concept may provide ways to effect sustainability transitions. We sought to define self-organisation by proposing three dimensions that might evidence it; by addressing these, in turn, in relation to our comparative case study, we have suggested how the two organisations differed according to these dimensions. Linking these to the importance of reflexive and communicative agency in the sustainability transition literature, we suggest how the initiatives' 
dimensions of self-organisation might promise the kinds of alliances, upscaling, and flexibility required to contest dominant waste-generative food systems, including public meanings around food wastage, charity and value [55].

By contextualising self-organisation, we have attempted to highlight the interplay of organisational agency and institutional structures affecting the growth and characteristics of surplus food redistribution. Our three-dimensional perspective suggests both synergies and trade-offs between the different aspects. 'Self-organisation', rather than existing as a reified category, can be used as a lens to characterise differences between initiatives claiming 'sustainability' potentials. Our analysis has incorporated a temporal perspective, echoing efforts in transition theory and practice to understand the constellations of actors, material environments and institutional arrangements that produce change over time.

Comparing the National Charity and SurplusCafé allows us to glimpse the seeds of what an effective anti-waste movement might look like, as well as ways in which movement dynamism can involve capture by dominant interests. Surplus food redistribution's appeal across the political spectrum gives it potential as a rallying point. That food wastage is integral to profit generation and worthy of critique, requiring radical systemic change if it is to be eliminated, provides the basis for discussions that might lead to a coherent plan of action. Empirically, this was not found to be (so far) the case. SurplusCafé's lack of a coherent political position (enabled by its autonomy) or means of developing one (through its governance) suggests that its steady, albeit fragmented, expansion is yet to effect a sustainability transition beyond very localised niches. However, it remains worthy of attention as evidence of a form of restlessness and organisational innovation which could lead to something more substantial.

A further avenue of study would be to examine the relationships between the models that we have compared in this paper. How, for example, are major food banking charities learning from their interactions with, and critiques by, more contestatory forms of surplus food redistribution by organisations such as SurplusCafé? Another important issue is how organisations focused on problems including wastage and food poverty, may form partnerships and alliances with diverse food system actors, such as the food sovereignty movement, in order to achieve the kind of institutional transformation that is required if the root causes of food waste and food insecurity are to be addressed.

Author Contributions: Conceptualisation, C.A.S. and R.B.; methodology, C.A.S.; formal analysis, C.A.S.; writing-original draft preparation, C.A.S. and R.B.; writing-review and editing, C.A.S. and R.B. All authors have read and agreed to the published version of the manuscript.

Funding: The analysis and writing was conducted under the auspices of the project Self-Organised Action for Food Equity (SAFE) which was financed by Mistra Urban Futures and implemented by the Urban Institute at the University of Sheffield in the UK and the Human Geography Unit at the University of Gothenburg in Sweden.

Acknowledgments: We thank the editors of the special issue and the reviewers for their critical but sympathetic comments which valuably contributed to the quality of the finished article. We also thank SAFE Gothenburg for funding the open access publication fee.

Conflicts of Interest: The authors declare no conflict of interest.

\section{References}

1. Davies, A.R.; Edwards, F.; Marovelli, B.; Morrow, O.; Rut, M.; Weymes, M. Making visible: Interrogating the performance of food sharing across 100 urban areas. Geoforum 2017, 86, 136-149. [CrossRef]

2. Schanes, K.; Stagl, S. Food waste fighters: What motivates people to engage in food sharing? J. Clean. Prod. 2019, 211, 1491-1501. [CrossRef]

3. Morrow, O. Community Self-Organizing and the Urban Food Commons in Berlin and New York. Sustainability 2019, 11, 3641. [CrossRef]

4. Davies, A.; Evans, D. Urban food sharing: Emerging geographies of production, consumption and exchange. Geoforum 2019, 99, 154-159. [CrossRef]

5. Loorbach, D.; Frantzeskaki, N.; Avelino, F. Sustainability Transitions Research: Transforming Science and Practice for Societal Change. Annu. Rev. Environ. Resour. 2017, 42, 599-626. [CrossRef] 
6. Durrant, R.; Barnes, J.; Kern, F.; Mackerron, G. The acceleration of transitions to urban sustainability: A case study of Brighton and Hove. Eur. Plan. Stud. 2018, 26, 1537-1558. [CrossRef]

7. Kemp, R.; Loorbach, D.; Rotmans, J. Transition management as a model for managing processes of co-evolution towards sustainable development. Int. J. Sustain. Dev. World Ecol. 2007, 14, 78-91. [CrossRef]

8. Fuchs, C. The Self-Organization of Social Movements. Syst. Pract. Action Res. 2006, 19, 101-137. [CrossRef]

9. Midgley, J.L. The logics of surplus food redistribution. J. Environ. Plan. Manag. 2014, 57, $1872-1892$. [CrossRef]

10. Poppendieck, J. Sweet Charity?: Emergency Food and the End of Entitlement; Penguin: Harmondsworth, UK, 1999.

11. Riches, G. Thinking and acting outside the charitable food box: Hunger and the right to food in rich societies. Dev. Pract. 2011, 21, 768-775. [CrossRef]

12. Lambie-Mumford, H. Hungry Britain: The Rise of Food Charity; Policy Press: Bristol, UK, 2017.

13. Riches, G. Food Banks and Food Security: Welfare Reform, Human Rights and Social Policy. Lessons from Canada? Soc. Policy Adm. 2002, 36, 648-663. [CrossRef]

14. Warshawsky, D.N. New power relations served here: The growth of food banking in Chicago. Geoforum 2010, 41, 763-775. [CrossRef]

15. Henderson, G. 'Free' Food, the Local Production of Worth, and the Circuit of Decommodification: A Value Theory of the Surplus. Environ. Plan. D Soc. Space 2004, 22, 485-512. [CrossRef]

16. Dowler, E. Food and Poverty in Britain: Rights and Responsibilities. Soc. Policy Adm. 2002, 36, 698-717. [CrossRef]

17. Tingay, R.S.; Tan, C.J.; Tan, N.C.W.; Tang, S.; Teoh, P.F.; Wong, R.; Gulliford, M.C. Food insecurity and low income in an English inner city. J. Public Health 2003, 25, 156-159. [CrossRef] [PubMed]

18. Cooper, N.; Purcell, S.; Jackson, R. Below the Breadline: The Relentless Rise of Food Poverty in Britain; OXFAM: Nairobi, Kenya, 2014.

19. Riches, G. Food Bank Nations: Poverty, Corporate Charity and the Right to Food, 1st ed.; Routledge: New York, NY, USA, 2018.

20. Spring, C. Learning Lessons from America's Surplus Food Redistribution Infrastructure; Report of Winston Churchill Memorial Trust Fellowship; Winston Churchill Memorial Trust: London, UK, 2016.

21. Patel, R. Survival pending revolution: What the black panthers can teach the US food movement. In Food Movements Unite!: Strategies to Transform Our Food System; Amin, S., Ed.; Food First Books: Oakland, CA, USA, 2011; pp. 115-136.

22. Cadieux, K.V.; Slocum, R. What does it mean to do food justice? J. Political Ecol. 2015, 22, 1-26. [CrossRef]

23. Gollnhofer, J.F. Normalising alternative practices: The recovery, distribution and consumption of food waste. J. Mark. Manag. 2017, 33, 624-643. [CrossRef]

24. Kropotkin, P. The Conquest of Bread; Vanguard Press: New York, NY, USA, 1926; p. 172.

25. Durrant, R.A. Civil Society Roles in Transition: Towards Sustainable Food? University of Sussex: Brighton, UK, 2014.

26. Michelini, L.; Principato, L.; Iasevoli, G. Understanding Food Sharing Models to Tackle Food Waste. Ecol. Econ. 2017, 2017, 205-217.

27. Edwards, F.; Mercer, D. Food waste in Australia: The freegan response. Sociol. Rev. 2012, 60, $174-191$. [CrossRef]

28. Barnard, A.V. Making the City "Second Nature": Freegan "Dumpster Divers" and the Materiality of Morality. AJS Am. J. Sociol. 2016, 121, 1017-1050. [CrossRef]

29. Giles, D.B. "A Mass Conspiracy to Feed People": Globalizing Cities, World-Class Waste, and the Biopolitics of Food Not Bombs. In Department of Anthropology; University of Washington: Seattle, WA, USA, 2013; p. 254.

30. Pel, B.; Bauler, T. The Institutionalization of Social Innovation: Between Transformation and Capture; TRANSIT working paper \#2; Transitsocialinnovation.eu: Rotterdam, The Netherlands, 2014; p. 18.

31. Hasanov, M.; Beaumont, J. The value of collective intentionality for understanding urban self-organization. Urban Res. Pract. 2016, 9, 231-249. [CrossRef]

32. Uitermark, J. Longing for Wikitopia: The study and politics of self-organisation. Urban Stud. 2015, 52, 2301-2312. [CrossRef] 
33. Edelenbos, J.; van Meerkerk, I.; Schenk, T. The Evolution of Community Self-Organization in Interaction with Government Institutions: Cross-Case Insights from Three Countries. Am. Rev. Public Adm. 2018, 48, 52-66. [CrossRef]

34. Denters, B. 11. Community self-organization: Potentials and pitfalls. In Critical Reflections on Interactive Governance: Self-Organization Participation in Public Governance; Edelenbos, J., van Meerkerk, I., Eds.; Edward Elgar Online: Cheltenham, UK, 2016; pp. 230-253.

35. Di Marzo Serugendo, G.; Foukia, N.; Hassas, S.; Karageorgos, A.; Mostéfaoui, S.K.; Rana, O.F.; Ulieru, M.; Valckenaers, P.; Van Aart, C. Self-Organisation: Paradigms and Applications; Springer: Berlin/Heidelberg, Germany, 2004.

36. Frenken, K.; Schor, J. Putting the sharing economy into perspective. Environ. Innov. Soc. Transit. 2017, 23, 3-10. [CrossRef]

37. Mair, J.; Reischauer, G. Capturing the dynamics of the sharing economy: Institutional research on the plural forms and practices of sharing economy organizations. Technol. Forecast. Soc. Chang. 2017, 125, 11-20. [CrossRef]

38. Kaufmann, M. Emergent self-organisation in emergencies: Resilience rationales in interconnected societies. Resilience 2013, 1, 53-68. [CrossRef]

39. Zebrowski, C.R. Governing the network society: A biopolitical critique of resilience. Political Perspect. 2009, 3.

40. Rauws, W. Civic initiatives in urban development: Self-governance versus self-organisation in planning practice. Town Plan. Rev. 2016, 87, 339-361. [CrossRef]

41. Ismael, J.T. Self-Organization and Self-Governance. Philos. Soc. Sci. 2011, 41, 327-351. [CrossRef]

42. Smith, A.; Raven, R. What is protective space? Reconsidering niches in transitions to sustainability. Res. Policy 2012, 41, 1025-1036. [CrossRef]

43. Arcuri, S. Food poverty, food waste and the consensus frame on charitable food redistribution in Italy. Agric. Hum. Values 2019, 36, 263-275. [CrossRef]

44. Hebinck, A.; Galli, F.; Arcuri, S.; Carroll, B.; O'Connor, D.; Oostindie, H. Capturing change in European food assistance practices: A transformative social innovation perspective. Local Environ. 2018, 23, 398-413. [CrossRef]

45. Garthwaite, K.; Spring, C.; Fisher, A. It's not the hungry who gain most from food banks-It's big business. The Guardian. 25 March 2019. Available online: https:/www.theguardian.com/commentisfree/2019/mar/25/ big-business-food-banks-subsidise-reputation (accessed on 15 June 2019).

46. Hawkes, C.; Webster, J. Too Much and Too Little? Debates on Surplus Food Redistribution; Sustain: London, UK, 2000.

47. Lougheed, S.; Spring, C. Conduits that bite back: Challenging the 'win-win' solutions of food recalls and redistribution. In Routledge Handbook of Food Waste, 1st ed.; Reynolds, C., Soma, T., Spring, C., Lazell, J., Eds.; Earthscan: London, UK, 2020; p. 520.

48. Avelino, F.; Wittmayer, J.M. The Transformative Potential of Plural Social Enterprise: A multi- actor perspective. In Theory of Social Enterprise and Pluralism: Social Movements, Solidarity Economy, and Global South; Eynaud, P., Laville, J.L., Dos Santos, S., Banerjee, F., Hulgård, L., Eds.; Routledge: Oxford, UK, 2019; pp. 193-222.

49. Spring, C.; Adams, M.; Hardman, M. Sites of learning: Exploring political ecologies and visceral pedagogies of surplus food redistribution in the UK. Policy Futures Educ. 2019, 17, 844-861. [CrossRef]

50. Bedore, M. Geographies of capital formation and rescaling: A historical-geographical approach to the food desert problem. Can. Geogr./Le Géogr. Can. 2013, 57, 133-153. [CrossRef]

51. Saxena, L.P.; Tornaghi, C. The Emergence of Social Supermarkets in Britain: Food Poverty, Food Waste and Austerity Retail; CAWR: Coventry, UK, 2018.

52. Milne, R. Arbiters of Waste: Date Labels, the Consumer and Knowing Good, Safe Food. Sociol. Rev. 2012, 60 (Suppl. 2), 84-101. [CrossRef]

53. Giles, D.B. The work of waste-making: Biopolitical labour and the myth of the global city. In Environmental Change and the World's Futures: Ecologies, Ontologies and Mythologies; Marshall, J., Connor, L., Eds.; Routledge: Abingdon, UK, 2016; pp. 81-95.

54. Conway, J.M.; Osterweil, M.; Thorburn, E.; Conway, J.M.; Osterweil, M.; Thorburn, E. Theorizing power, difference and the politics of social change: Problems and possibilities in assemblage thinking (introductory essay). Stud. Soc. Justice 2018, 12, 1-18. [CrossRef] 
55. Unger, R.M. Conclusion: The task of the social innovation movement. In New Frontiers in Social Innovation Research; Nicholls, A., Simon, J., Gabriel, M., Eds.; Palgrave Macmillan: New York, NY, USA, 2015; pp. $233-251$.

56. Midgley, J.L.; Jeffries, J.; Aitken, D.; Dravers, N.; Skinner, M. A Recipe for Success? Identifying Social and Community Impacts in the Work of Community Cafés:The Case of RE-FUSE Pay as You Feel Café; University of Newcastle: Newcastle upon Tyne, UK, 2018.

57. Haxeltine, A.; Pel, B.; Dumitru, A.; Avelino, F.; Kemp, R.; Bauler, T.; Kunze, I.; Dorland, J.; Wittmayer, J.; Jørgensen, M.S. Towards a TSI theory: A relational framework and 12 propositions. In TRANSIT Working Paper; Trans Tech Publications Ltd.: Stafa-Zurich, Switzerland, 2017; pp. 1-2.

(C) 2020 by the authors. Licensee MDPI, Basel, Switzerland. This article is an open access article distributed under the terms and conditions of the Creative Commons Attribution (CC BY) license (http://creativecommons.org/licenses/by/4.0/). 